\title{
Cultural heritage and the environment
}

\author{
R. Van Grieken, F. Delalieux and K. Gysels \\ University of Antwerp (U.I.A), Department of Chemistry, Universiteitsplein 1, B-2610 Antwerpen, Belgium
}

Abstract: Air pollution can have a significant influence on the weathering of monuments and on the deterioration of museum objects and prehistoric cave paintings. Three important mechanisms of stone weathering will be discussed, and an overview of analysis techniques invoked for the assessment of the degradation processes will be given. The effects of several air pollutants on works of art are reviewed, illustrated with examples of the micro-analysis of aerosols in two European museums. The influence of tourism on the preservation of prehistoric rock art is also addressed.

\section{INTRODUCTION}

Air pollution can significantly affect the corrosion of materials. In the USA, it has been estimated that some $4 \%$ of the GNP goes to restoring the damage of corrosion, and that about half of this could have been avoided, i.e. is due to anthropogenic causes. Various valuable and often irreplaceable cultural heritage items do, of course, also undergo the deleterious effects of air pollution, with different rates, vulnerabilities and restoration costs involved.

Indoor air pollution, a consequence of both indoor and outdoor factors, can cause chemical damage or soiling onto surfaces of paintings, frescoes, sculptures etc., by deposition of particulate material or absorption of present gases. Also prehistoric cave paintings can be affected by air pollution. The conservation of our cultural heritage and its protection against possible damage due to indoor air pollution has only recently received growing scientific interest.

\section{DECAY PROCESSES OF STONE}

Stone decay takes many different forms. Sometimes the stone weathers away gradually, sometimes large scales of stone drop away in one go. The surface may erupt into blisters or the stone may loose all integrity. The stone may even look perfectly sound, while below the surface it has lost its cohesion. Many factors contribute to this decay. The composition of the stone and the particular environment in which it is found are the main categories in which they can be divided. They will determine the type and rate of deterioration (ref. 1). The degree of alteration depends on the weatherability of the minerals, that constitute the rock, on the homogeneity and the specific surface exposed area (ref. 2). In nature, rocks deteriorate continuously as a result of physical, chemical, mechanical and biological processes, depending on e.g.: air constituents, relative humidity, temperature, wind velocity, solar radiation, frequency and intensity of rain, sea spray, deicing salts, composition of the soil, living organisms.

\section{Stone decay by air pollution}

The acceleration of decay in urban stone monuments in the 70's and 80 's has been attributed to the sharp increase of air pollutants (ref. 3). Building stone is most affected by acid air pollution when it contains a high amount of calcite $\left(\mathrm{CaCO}_{3}\right)$, like marbles, limestones, sandstones and mortars. The natural compounds and artificial pollutants most relevant to stone decay are: carbon dioxide, sulphur oxides, nitrogen oxides, particulate matter, ammonia, ozone, hydrogen fluoride and hydrogen chloride (ref. 3). Most research has focussed on the first three compounds, all capable of dissolving in water and reacting with calcareous materials (ref. 4). Pollutants are removed from the atmosphere by either dry (settleable particulates, aerosols and gases) or wet deposition (via rain and snow). The dry deposition is intimately related to the air quality in the immediate vicinity of the receptor. Wet deposition comprises the incorporation of trace substances in cloud droplets (rainout) and removal by falling precipitation (washout). It is also related to

*Lecture presented at the XI CHEMRAWN Meeting on Environmental Chemistry: Latin American Symposium on Environmental Analytical Chemistry, Montevideo, Uruguay, 15-20 March 1998.

Other presentations are published in this issue, pp. 2259-2336. 
the air concentration, although the relationship is very complicated. Both depositions can cause significant deterioration of stonework. The relative importance of dry and wet deposition to stone damage depends on the pollution and climate, with dry deposition being relatively more important in heavily polluted areas.

Sulphur dioxide is the primary pollutant involved in stone decay: it results in sulphate formation on stone (ref. 3). Concentrations of $\mathrm{SO}_{2}$ have declined markedly in recent decades, but, in spite of this, high rates of material damage are still reported. The surface of porous stone may have been altered permanently in unwashed walls by past exposure to high pollutant levels and the present high rate indicates a memory effect of the previous exposure. Sulphation involves the dry deposition reaction between $\mathrm{SO}_{2}$ gas and the limestone itself, in the presence of high relative humidity, an oxidant and a catalyst (metal oxide, such as $\mathrm{Fe}_{2} \mathrm{O}_{3}$ or even $\mathrm{NO}_{2}$ ).

$$
\mathrm{CaCO}_{3}+\mathrm{SO}_{2}+2 \mathrm{H}_{2} \mathrm{O}+1 / 2 \mathrm{O}_{2} \rightarrow \mathrm{CaSO}_{4} \cdot 2 \mathrm{H}_{2} \mathrm{O}+\mathrm{CO}_{2}
$$

The end product (gypsum) is well known but little is known about the intermediate steps. Probably, the most important process is the heterogeneous oxidation of sulphur dioxide in the aqueous phase, which occurs in the atmosphere or on the surface. Depending on the immediate environment of the stone, the gypsum layer is washed away and the surface recedes (often at a rate of $10 \mu \mathrm{m} / \mathrm{y}$ or more), since gypsum is far more soluble in water than calcite $(2.4$ versus $0.014 \mathrm{~g} / \mathrm{L})$, or it accumulates and may form black crusts (ref. 4). Carbonaceous particles, characteristic of oil-fired emissions, are absorbed in the gypsum layer and are responsible for the blackness; they have an enormous specific area and contain metals, which catalyse the formation of black crusts. They can behave not only as carriers of chemicals, but also as gypsumnucleating agents. Fly ash participates as well in stone sulphur fixation, since it contains $\mathrm{V}, \mathrm{Fe}, \mathrm{Cu}, \mathrm{Cr}$ and $\mathrm{Mn}$, which catalyse the conversion of $\mathrm{SO}_{2}$ into sulphate.

Carbon dioxide is by far the most abundant of all atmospheric gases generated by human activities. It dissolves in rainwater, forming the weakly acidic solution $\mathrm{CO}_{2} \cdot \mathrm{H}_{2} \mathrm{O}$ (liq), which leaches the calcite matrix from e.g. marbles and limestones.

Little nitrate is found in stone surfaces, although nitrogen oxides contribute a significant amount to the total loading of air pollution. Thermodynamics suggest that the nitrate reaction would not be favoured. The difficulty in finding $\mathrm{Ca}\left(\mathrm{NO}_{3}\right)_{2}$ on calcareous rock is probably also due to its high solubility in water. Sikiotis and Kirkitsos (ref. 5) state, however, that the corrosive action of nitrates and sulphates is comparable on Pentelic marble. Maybe the most important role of nitrogen oxides is in the catalytic oxidation of $\mathrm{SO}_{2}$ (ref. 2). The synergistic effect of nitrogen oxides and $\mathrm{SO}_{2}$ has been observed at high, but not at low humidities.

Between 15 and $20 \%$ of the global aerosols (defined as liquid and solid substances dispersed in the air) seems to be of anthropogenic origin. They are directly emitted or originate from gas-phase conversions within the atmosphere. Industry, traffic and agriculture are important emitters of aerosols larger than $1 \mu \mathrm{m}$. Gases can become liquid or solid particles by cooling or chemical reactions in the atmosphere. The remaining 80 to $85 \%$ are of natural origin. The amount emitted directly (sea salt, wind-blown dust, volcanic emission, forest fire) is approximately equal to that originating from gas-phase conversions. Suspended particulate matter can be dangerous for the stone in that it can soil surfaces, both causing aesthetic damage (blackening of the stone) and creating ideal conditions for oxidation processes. The surface roughness of stone enhances the deposition of particles. Since gypsum is present in aerosols, a part of it may be deposited.

\section{Effect of salts on stone weathering}

Stonework can become contaminated with salts in many ways: air pollution is a major source of sulphates and nitrates, rising damp may carry salts, dissolved in the soil, wind transports salts from the sea; deicing salt, unsuitable cleaning material and incompatible building material can also be considered as sources (ref. 4). Salt damage is largely attributable to two mechanisms: crystallization of salts from solution and hydration of salts, that can exist in more than one hydration state. Thermal expansion of the salts is a third, less important factor. The growth of salt crystals within pores can cause stresses, which are sufficient to overcome the stone's tensile strength (ref. 4). When the migration of the salt to the surface of the stone is faster than the rate of drying, the crystals deposit on the top of the external surface and form visible 
efflorescences, which do not damage the stone. When the migration is slower than the drying rate, the solute crystallizes within the pores, at varying depth, causing crumbling and powdering of the stone.

\section{Biodeterioration of stone}

Biodeterioration is a factor of increasing importance in a cleaner atmosphere. Various bacteria, cyanobacteria, algae, fungi and lichens have been found to be involved in the degradation of rocks. An overview about biological stone decay is given in e.g. (ref. 6).

Lichens are pioneer organisms to colonize stone surfaces. The effects of lichens are mechanical and chemical. Mechanical damage is caused by penetration of the hyphae into the stone and by expansion and contraction of the thallus under changes of humidity. Many micro-organisms are in fact capable, through a range of etching and chelating processes, to bore and burrow their way into mineral surfaces, producing pits and channels. Chemical damage is more important and may arise by excretion of oxalic acid and generation of carbonic and other acids. These acids are capable of chelating metal ions such as calcium and magnesium (ref. 4) or they replace monovalent cations in the mineral with protons. Lichens are extremely sensitive to gaseous sulphur compounds of sulphur and ozonated hydrocarbons, which account for their scarcity in urban areas. Bacteria attack the stone chemically. Autotrophic bacteria derive their carbon from $\mathrm{CO}_{2}$ and their energy from light or chemical redox reactions; some are capable of oxidising sulphur and nitrogen compounds to produce sulphuric and nitric acid. Nitrifying bacteria oxidize $\mathrm{NH}_{4}{ }^{+}$-ions in solution forming nitrates. Heterotrophic bacteria utilize organic compounds to derive their carbon and produce chelating agents and weak organic acids. Although e.g. cyanobacteria release only $\mathrm{CO}_{2}$, they increase the dissolving ability of water on the stone.

\section{ANALYSIS OF DEGRADATION PROCESSES}

It is essential to be able to quantify the decay mechanisms that act on historical building stones, and to understand which factors are relevant for the degeneration. Quantitative degradation rates can be monitored in laboratory experiments, field exposure trials or on monument surfaces themselves over time, using techniques that monitor surface roughness changes, recession rates, and/or chemical changes (ref. 7).

The bulk inorganic composition of deteriorated materials can be determined by many analysis techniques. Among them X-ray Fluorescence spectroscopy (XRF) and Ion Chromatography (IC) have emerged as being very useful in this context for rapid trace element screening and anion determinations, respectively. During the last decades, a broad range of microanalytical and surface techniques has additionally become available, which can be applied advantageously to study the deterioration mechanisms of different cultural heritage artefacts. Early stages of deterioration can be detected. When weathering processes, which have to go on for many years before showing apparent damage, are to be monitored over relatively short time intervals or when such processes are simulated in the laboratory, it is essential to use techniques permitting measurement of chemical alteration in the uppermost layer of the surface or even of microscopic spots on it. Scanning Electron Microscopy (SEM) has already been used extensively, while the application of the related technique of Electron Microprobe Analysis (EMPA) in this field is still growing. However, other micro-analytical techniques, like e.g. Laser Microprobe Mass Spectrometry (LMMS), Fourier Transform Infrared Spectrometry (FTIR), X-ray Photo-electron spectroscopy (XPS), Proton Induced X-ray Emission (PIXE) show good prospects, although their use has only been reported in a few publications. The application of Secondary Ion Mass Spectrometry (SIMS) has been explored recently, while Nuclear Reaction Analysis (NRA), Auger Electron Spectroscopy (AES) and Raman Laser Microprobe Analysis (RLMP) have been used by some individual authors.

\section{EFFECTS OF AIR POLLUTION ON MUSEUM OBJECTS}

The indoor environment - micro-climate and air pollution - can have a significant influence on the works of art exhibited in museums. Daily temperature and relative humidity cycles, induced by forced heating and air-conditioning, cause mechanical stress. Moreover, crystallization of salts in the micropores of the paintings can cause further damage (ref. 8). Gaseous and particulate pollutants can also play an important role in the deterioration of museum objects. The main deteriorating effect of $\mathrm{SO}_{2}$ arises from oxidation to 
$\mathrm{H}_{2} \mathrm{SO}_{4}$ (ref. 9). It leads to fading of pigments, paper and textile can be damaged, and the corrosion of metals is accelerated. $\mathrm{H}_{2} \mathrm{~S}$ causes tarnishing of silver objects, and like other reduced sulfur gases (mercaptans, sulfides, disulfides, carbonyl sulfide, carbon disulfide), it can contribute indirectly to the fading of colours when it is oxidised to $\mathrm{SO}_{2}$ (ref. 10). $\mathrm{O}_{3}$ is also responsible for fading of dye (ref. 11) and it can cause damage to varnish (ref. 9). Pigment fading, as well as degradation of textile and paper, and metal corrosion can also be induced by $\mathrm{NO}_{2}$ (ref. 12). The deterioration mechanism can be attributed to oxidation to $\mathrm{HNO}_{3}$ (ref. 12). Another pollutant that should be taken into account is HCHO. It can be released by construction materials and can cause deterioration of metal objects (ref. 13).

Deposition of particulate matter onto the paintings can lead to significant soiling, and chemical reactions with the deposited particles can cause further damage. The deposition flux (i.e. the number of particles, that is deposited per unit surface and unit time) is a function of the diameter and the concentration of the particles, and several other factors like temperature and moisture gradients, air turbulence, temperature, relative humidity and the surface characteristics. Several deposition mechanisms exist, all with a maximum in a specific size range (ref. 8). Brownian deposition is especially important in the smallest size fraction (< $0.1 \mu \mathrm{m})$. Thermophoresis, active in the submicronic size range, can counteract the Brownian deposition when the surface is warmer than the air, but the largest particles $(>1 \mu \mathrm{m})$ will still be deposited due to aerodynamic impaction. Electrophoresis and Stefan flow are additional deposition mechanisms, active in the presence of an electric field and evaporation or condensation processes, respectively. Large particles are also subject to gravitational settling, which will cause soiling of horizontal surfaces. This effect is reduced in the presence of air turbulence.

The damage caused by the deposited particles depends on their chemical composition. Soot can be considered very harmful because it causes significant blackening (ref. 14) and, together with other organic compounds, it constitutes a medium for $\mathrm{SO}_{2}$ absorption (ref. 15). These effects can be even more enhanced by $\mathrm{CaSO}_{4}$, which has been found to absorb soot (ref. 16). Also Fe-rich particles can have a negative effect on the paintings, due to their catalytic role in the oxidation of $\mathrm{SO}_{2}$ to $\mathrm{H}_{2} \mathrm{SO}_{4}$ (ref. 9). $\left(\mathrm{NH}_{4}\right)_{2} \mathrm{SO}_{4}$ can induce bloom on varnish (ref. 13). Characterization of the particle types present in the different size classes of the aerosol present in the museum can therefore contribute to the future prevention of deterioration of the works of art.

Size-segregated aerosol samples $(1-20 \mu \mathrm{m})$ have been collected in two European museums. The individual particles present in these samples were analysed by Scanning Electron Microscopy with Energydispersive X-ray Detection (SEM-EDX). In the Correr Museum, Venice, Italy, the aerosol consisted largely of $\mathrm{Ca}$-rich and $\mathrm{Ca}-\mathrm{Si}$ particles, originating from degradation of the building material, i.e. the rendering on the walls. The size class $0.5-1 \mu \mathrm{m}$ contained more organic and S-rich particles, which can be considered very harmful. These particles originate from the outdoor environment. Completely different results were obtained for the Sainsbury Centre for Visual Arts, Norwich, UK, a very modern building, composed of aluminum and glass. The outdoor atmosphere was the most important source of indoor particles, although some indoor sources of organic particles were also present. The restaurant area is not clearly separated from the exhibition area and could be of influence. The presence of a carpet was also found to have a negative influence, in both museums, as particles can be trapped by it, and later resuspended when people walk on it.

\section{DETERIORATION OF PREHISTORIC ROCK ART}

Ever since caves containing prehistoric rock art have been opened to the public, the paintings have been subject to deterioration. Several factors could be responsible for this phenomenon. Public access implicates a modification of the natural equilibrium that has been established in the caves over the centuries (ref. 17). Instead of the smooth seasonal cycles, relatively large diurnal temperature and relative humidity variations occur. Moreover, $\mathrm{CO}_{2}$ and $\mathrm{H}_{2} \mathrm{O}$ are emitted in the presence of visitors, influencing the $\mathrm{Ca}\left(\mathrm{HCO}_{3}\right)_{2}-\mathrm{CaCO}_{3}$ equilibrium in the water film covering the paintings. The electric lighting causes a supplementary biological growth. Microbiological contamination can cause severe damage to the rock paintings (ref. 18). Air pollution and infiltration of rainwater could also be of influence. Further deterioration can be prevented by a reduction of the number of visitors or even by completely closing the cave to the public. The last option was chosen in Lascaux, where biological contamination caused significant damage (ref. 18). 
In order to assess the effects of air pollution and percolation water on the deterioration of the paintings, aerosol and water samples have been collected in the caves of Altamira and Tito Bustillo, in the North of Spain, and the Grotta dei Cervi, in the South of Italy. The aerosol samples and the suspended particles present in the water samples were analyzed by SEM-EDX. Both the atmospheric and the aqueous suspended particulate matter consisted mainly of calcite, aluminosilicates (clay) and some organic matter. No pigment particles were encountered in the water samples percolating the pictures. A large difference was found between the composition of the aerosol samples collected in the Altamira cave and just outside, so outdoor air pollution does not constitute a main contribution to the cave environment and does not have a significant influence on the deterioration of the Altamira paintings. It appears that microbiological activity (probably based on the high organic matter content of the percolating rain water) is of utmost importance.

\section{REFERENCES}

1. A.E. Charola. In Air Pollution and Conservation, Safeguarding our Architectural Heritage (J. Rosvall, S. Aleby, eds.), pp. 125-132. Elsevier, Amsterdam (1988).

2. G.G. Amoroso, V. Fassina. Stone Decay and Conservation: Atmospheric Pollution, Cleaning, Consolidation and Protection. Materials Science Monographs 11, Elsevier, Amsterdam, (1983).

3. V. Fassina. In Air Pollution and Conservation, Safeguarding our Architectural Heritage (J. Rosvall, S. Aleby, eds.), pp. 133-174. Elsevier, Amsterdam (1988).

4. C.A. Price. Stone Conservation, an Overview of Current Research. J. Paul Getty Trust Publications, Santa Monica, California, (1996).

5. D. Sikiotis, P. Kirkitsos. Sci. Total Environ. 171, 173-182 (1995).

6. W.E. Krumbein. In Air Pollution and Conservation, Safeguarding our Architectural Heritage (J. Rosvall, S. Aleby, eds.), pp. 175-198. Elsevier, Amsterdam (1988).

7. D. Camuffo, S. Fitz, B. Fitzner, O. Lindqvist, R.A. Livingston, P.-N.V. Maravelaki, C. Sabbioni, H.A. Viles, T. Warscheid. In Saving Our Architectural Heritage: The Conservation of Historic Stone Structures (N.S. Baer and R. Snethlage, eds.), pp. 95-112. John Wiley \& Sons, New York (1997).

8. D. Camuffo. Microclimate for Cultural Heritage. Elsevier, Amsterdam (1998).

9. G. Thomson. Stud. Cons. 10, 147-167, (1965).

10. M.W.M. Hisham, D. Grosjean. Atmos. Envir. 25A, 1497-1505 (1991).

11. D. Grosjean, E. Grosjean, E.L. Williams II. Atmos. Envir. 27A, 765-772 (1993).

12. L.G. Salmon, W.W. Nazaroff, M.P. Ligocki, M.C. Jones, G.R. Cass. Envir. Sci. Technol. 24, 1004-1013 (1990).

13. P. Brimblecombe. Atmos. Envir. 24B, 1-8 (1990).

14. N.S. Baer, P.N. Banks. Int. J. Museum Management Curatorship 4, 9-20 (1985).

15. R.I. Larson. Am. Paint J. 42, 94-108 (1957).

16. L. Leysen, E. Roekens, Z. Komy, R. Van Grieken. Anal. Chim. Acta 195, 247-255 (1987).

17. J. Brunet, P. Vidal. Stud. Cons. 25, 97-107 (1980).

18. M. Lefèvre. Stud. Cons. 19, 126-156 (1974). 